\title{
A IMAGEM DA CIDADE: O CENTRO DE PRESIDENTE PRUDENTE EM MAPAS MENTAIS
}

Rogério Penna Quintanilha, Henrique Luiz de Oliveira, Thaís Calixtro da Rocha Ventura.

Universidade do Oeste Paulista - UNOESTE, Faculdade de Engenharias e Arquitetura e, Presidente

Prudente, SP. E-mail: arq.rogerio@gmail.com

\section{RESUMO}

O presente trabalho procura discutir a imagem do centro da cidade de Presidente Prudente conforme a base teórica e metodologia aplicada por Kevin Lynch no livro A Imagem da Cidade (2010). Para tanto, foram utilizados 235 mapas mentais desenvolvidos nas disciplinas de Urbanismo do curso de Arquitetura e Urbanismo da Universidade do Oeste Paulista entre 2011 e 2013. Os mapas foram analisados e tabulados pelo grupo, identificando ruas, lugares e sensações conforme o número de ocorrências. A partir dos resultados, discute-se possíveis direcionamentos de planejamento urbano que, a partir desta perspectiva, contribuiriam para um fortalecimento desta imagem. $\mathrm{O}$ artigo apresenta tabelas parciais com os principais resultados.

Palavras Chave: Kevin Lynch; Urbanismo; Presidente Prudente; Mapas Mentais; Centro da Cidade;

\section{THE IMAGE OF THE CITY: MIND MAPS OF THE PRESIDENTE PRUDENTE DOWNTOWN.}

\begin{abstract}
This paper discusses the image of the Presidente Prudente city downtown as the theoric basis and methodology applied by Kevin Lynch in his book The Image of the City. Therefore, we used 235 mind maps developed in Urban Design disciplines of Architecture and Urban Design at the Universidade do Oeste Paulista, between 2011 and 2013. The maps were analyzed and tabulated by the group, identifying streets, places and sensations by the number of occurrences. From the results, we discuss possible urban planning directions that, from this perspective, would contribute to the strengthening of this image. The article presents partial tables with the main results.
\end{abstract}

Keywords: Kevin Lynch; Urban Design; Presidente Prudente; Mind Maps; Downtown; 


\section{INTRODUÇÃo}

As cidades são percebidas de formas diferentes pelas pessoas. Essa percepção, embora parta da cidade física, é também uma construção mental que fazemos sobre ela e que pode corresponder ou não à realidade. Compõe essa projeção nossas experiências, nossas expectativas, memórias e todo o tipo de grandes ou pequenas sensações relacionadas a ela. A menção do nome da cidade onde nascemos nos trás uma sensação - uma imagem - relacionada à nossa infância. Talvez a cidade tenha mudado tanto que a imagem que fazemos dela já não corresponde em nada com a realidade. Uma cidade em que nunca estivemos - talvez, Paris, ou Tóquio, ou Moscou também nos remete a imagens que relacionamos a cada uma, mesmo que não tenhamos nenhuma experiência delas. $E$, é claro, a menção à cidade em que vivemos - aqui, Presidente Prudente - nos provoca mentalmente uma imagem relacionada à nossa experiência cotidiana.

Para Lynch (2010), a IDENTIDADE de um local - rua, bairro ou cidade - é composta de alguns elementos. Em primeiro lugar, a sua INDIVIDUALIDADE e PARTICULARIDADE, ou seja, a existência de fenômenos únicos ou raros que aconteçam naquele local. O encontro do mar com a montanha no Rio de Janeiro, os gondoleiros de Veneza, a arquitetura de Brasília e os artistas de rua nos bulevares de Paris são únicos e reconhecidos imediatamente. Além disso, a sua ESTRUTURA, ou seja, a legibilidade e clareza de sua malha e de seus pontos de referência urbanos ajudam a consolidar essa identidade. Finalmente, o SIGNIFICADO ou as relações construídas a partir da experiência de cada lugar - caminhos que percorremos, lugares que frequentamos, memórias que acumulamos - bem como a facilidade ou dificuldade em construir essas relações, fazem parte da formação da mesma identidade. Assim, Lynch desenvolve o método dos mapas mentais como uma pesquisa cujo objetivo é identificar a imagem coletiva sobre um bairro ou cidade e, dessa forma, fornecer subsídios para intervenções. Em seu livro, Lynch dá exemplos dessa forma de pesquisa em cidades americanas como Boston e Nova Jersey, e há casos de pesquisas semelhantes no Brasil. Em Presidente Prudente, claramente não há nenhuma preocupação quanto a esse modo de ver a cidade nas reformas urbanas executadas, como exemplo a demolição do coreto da praça 9 de Julho, ponto extremamente simbólico para os moradores, que, assim como outros, vêm demonstrar.

Sendo a obra de Kevin Lynch um dos temas trabalhados na disciplina de Urbanismo III no curso de Arquitetura e Urbanismo da UNOESTE, ao longo de sucessivos semestres, entre 2011 e 2013, 235 mapas mentais foram realizados, parte pelos próprios alunos de graduação, parte por outras pessoas por eles solicitadas e catalogados separadamente. Posteriormente entregues ao professor responsável, acumularam-se de tal forma que uma outra pesquisa, mais longa e aprofundada, tornou-se possível. Portanto, o presente artigo pretende catalogar e discutir esses resultados contribuindo na apresentação de um outro ponto de vista sobre a cidade que deveria ser considerado na elaboração de políticas urbanas. Além disso, mesmo ainda que limitado ao centro da cidade, a experiência fornecerá requisitos para que outras áreas da cidade sejam igualmente estudadas, segundo o mesmo método.

\section{METODOLOGIA}

Os 235 mapas mentais foram produzidos por diversos alunos entre 2011 e 2013, entrevistando pessoas diversas de sua convivência, residentes ou não em Presidente Prudente, e não trazem qualquer identificação de seu autor. A pesquisa consistia em solicitar que se fizesse um mapa do centro de Presidente Prudente, com suas ruas principais e pontos de referência. Cada um poderia também enriquecer o mapa com sensações ou sentimentos que lhe viessem à mente. Finalmente, pedia-se que o pesquisado indicasse, no mapa, onde jugava estar a direção norte.

De posse desses mapas acumulados ao longo dos semestres, foram contados o número de vezes em que apareciam determinados elementos, nas categorias Norte/Abrangência, Ruas $e$ Avenidas, Lugares e Sensações. No primeiro item, interessava saber qual a abrangência da área 
identificada pelo entrevistado vagamente definida como Centro da cidade, bem como a precisão em apontar a direção norte em seu mapa. No segundo, quais e quantas vezes vias apareceram como referência, o mesmo valendo para os lugares no terceiro item, acrescidos ou não por sensações.

\section{RESULTADOS}

A pesquisa revelou as tabelas a seguir. Por conveniência, estão listadas aqui apenas as aparições mais frequentes.

Tabela 01. Abrangência do mapa

\section{Abrangência do Mapa}

\begin{tabular}{|l|l|}
\hline Menor que o quadrilátero central - em torno do calçadão & 60 \\
\hline Menor que o quadrilátero central - em torno da Praça 09 de Julho & 53 \\
\hline Igual ao quadrilátero central & 35 \\
\hline Menor que o quadrilátero central - em torno da Avenida Cel. Marcondes & 22 \\
\hline Menor que o quadrilátero central - em torno da Catedral & 16 \\
\hline Menor que o quadrilátero central - em torno do pontilhão (Camelódromo) & 4 \\
\hline Maior do que o quadrilátero central & 18 \\
\hline
\end{tabular}

Tabela 02. Apontamento da direção norte

\begin{tabular}{|l|l|l|l|l|l|}
\hline Apontamento da direção norte & 42 & Noroeste & 21 & Sudoeste & 14 \\
\hline Nordeste & 41 & Sudeste & 19 & Oeste & 12 \\
\hline Lorte & 23 & Sul & 16 & NULO & 43 \\
\hline
\end{tabular}

Tabela 03. Ocorrência de ruas e avenidas

\section{Ruas e Avenidas}

\begin{tabular}{|c|c|c|c|}
\hline Ocorrência & Qtde & Ocorrência & Qtde \\
\hline Calçadão & 158 & R. Dr. Gurgel & 36 \\
\hline Avenida Coronel Marcondes & 126 & R. Rui Barbosa & 30 \\
\hline Avenida Brasil & 102 & R. Tenente Nicolau Maffei & 29 \\
\hline Avenida Washington Luiz & 89 & R. Joaquim Nabuco & 22 \\
\hline Avenida Manoel Goulart & 89 & R. Siqueira Campos & 20 \\
\hline R. Barão do Rio Branco & 58 & R. Dr. José Foz & 19 \\
\hline
\end{tabular}


Tabela 04. Ocorrência de sensações mais citadas

Locais - Sensações mais citadas

\begin{tabular}{|l|l|l|l|l|l|}
\hline \multicolumn{2}{|l|}{ Praça 9 de Julho } & \multicolumn{2}{l|}{ Catedral } & \multicolumn{2}{l|}{ Praça Monsenhor Sarrion } \\
\hline Sensação & Qtde & Sensação & Qtde & Sensação & Qtde \\
\hline Pombos & 10 & Paz & 13 & Pombos & 15 \\
\hline Frescor & 6 & Calma & 4 & Cheiro de pipoca & 7 \\
\hline Posto Policial (Pç 9 de Jul.) & Camelódromo & & Calçadão & \\
\hline Insegurança & 3 & Fedor & 6 & Muita gente & 23 \\
\hline Segurança & 2 & Bagunça & 5 & Calor & 21 \\
\hline
\end{tabular}

Tabela 05. Ocorrência de lugares mais citados

\begin{tabular}{|c|c|c|c|}
\hline \multicolumn{4}{|c|}{ Lugares mais frequentemente citados } \\
\hline Ocorrência & Qtde & Ocorrência & Qtde \\
\hline Catedral & 154 & Drogasil (Joaquim Nabuco) & 20 \\
\hline Praça 9 de Julho & 128 & Praça Sarrion & 20 \\
\hline Prefeitura & 101 & Rodoviária & 19 \\
\hline Camelódromo & 98 & Cultura Inglesa & 18 \\
\hline Posto Policial (Praça 9 de Julho) & 62 & Torra Torra & 18 \\
\hline Bombeiros & 50 & CEF (Coronel Marcondes) & 17 \\
\hline Banco do Brasil (Calçadão) & 43 & Terminal & 13 \\
\hline Ponto de ônibus (Catedral) & 35 & Arruda Mello & 12 \\
\hline Chic Center & 30 & Praça da Bandeira & 12 \\
\hline Correios & 26 & Fórum (Procuradoria) & 11 \\
\hline Tanger & 22 & Hotel Aruá & 11 \\
\hline Farmácia (Praça 9 de Julho) & 21 & Ponto de ônibus (Praça 09 jul.) & 11 \\
\hline
\end{tabular}

\section{DISCUSSÃO}

Oficialmente, o centro de Presidente Prudente ultrapassa o quadrilátero central formado pelas avenidas Manoel Goulart, Brasil, Washington Luís e Cel. Marcondes. No imaginário coletivo, entretanto, os limites do centro são menores do que estes (151), centrados em torno do calçadão (60) ou da Praça 9 de Julho (53), que surgem desde o início como os pontos de referência mais importantes, juntamente com a Catedral (154), Prefeitura (101) e Camelódromo (98). A via mais citada em números absolutos é o Calçadão (158), seguido pelas quatro avenidas citadas, Cel. 
Marcondes (126), Brasil (102), Manoel Goulart (89) e Washington Luís (89). Notadamente, dos 10 locais mais citados, 8 estão na Avenida Cel. Marcondes e apenas o Camelódromo está distante dela. Entretanto, a despeito de sua importância imagética, as sensações relacionadas a ela são normalmente desagradáveis: trânsito, estresse, movimento e barulho. De fato, a única via que sugere sensações agradáveis é a Av. Washington Luís, algumas vezes citada como limpa (1), moderna (1), ou destacada por seus serviços médicos (4).

Ainda sobre os limites e sistema viário, é notável a forma como apenas 4 mapas ultrapassaram a Avenida Brasil, a Praça da Bandeira e o Camelódromo, incluindo a Vila Marcondes e edifícios que estão além da linha férrea como parte do centro. De fato, nem mesmo a linha férrea é citada, bem como edifícios importantes como o Centro Cultural Matarazzo e o Instituto Brasileiro do Café (IBC), completamente ausentes dos mapas embora sejam bem mais próximas do centro do que, por exemplo, o Prudenshopping, que aparece 8 vezes. Este dado se confronta com a pesquisa de BORGES (2016), especificamente com moradores da Vila Marcondes e de bairros além da linha que frequentemente se representavam nos mapas mentais do centro. Entende-se assim, que a visão de moradores de um lado e do outro da linha férrea difere no papel desta como limite da região central, relação reforçada pelas diferenças topográficas, arquitetônicas, urbanísticas e históricas de formação da cidade como duas vilas distintas separadas exatamente pelo caminho do trem.

Dentre os locais mais frequentemente lembrados, a Catedral ocupa posição de destaque (154), normalmente relacionada a sensações agradáveis como Paz (13), Calma (4) e Tranquilidade (4). A Praça 9 de Julho, citada em 128 mapas, foi também expressamente desenhada 50 vezes, normalmente em planta baixa com um círculo ao centro, destacando a fonte como elemento simbólico vinculado à identidade do local. Ainda nela, nota-se o caráter ambíguo da presença do posto policial, relacionado tanto a segurança (3) quanto a insegurança (2). O edifício da prefeitura municipal, também muito citado (101), possui bem menos sensações associadas, algumas delas revelando certo descontentamento não exatamente relacionado ao espaço físico como Corrupção (2), Egoísmo (1) e Esquecimento (1). Os pontos comerciais mais citados são de característica popular como as lojas Chic Center (30), Tanger (22) e Torra Torra (18). Outros destaques são a Drogasil (20), referência por seus muitos anos de existência e atendimento 24 horas e a escola de inglês CNA (18) que, embora não seja popular ocupa (inclusive com um grande anúncio na fachada) um ponto fundamental na esquina entre as avenidas Cel. Marcondes e Washington Luís. É curioso, entretanto, que outros pontos na mesma esquina que teriam até mais importância histórica são menos citados, o I.E. Fernando Costa (5), o Hotel Aruá (11), e a antiga biblioteca municipal, atual Secretaria de Saúde e futura Câmara dos Deputados, citada apenas uma vez. Outros edifícios de grande importância histórica foram, relativamente, pouco citados, como o antigo Fórum, atual Procuradoria (11), muito menos citado que o seu vizinho Corpo de Bombeiros (50), o antigo colégio E.E. Prof. Arruda Mello (12), o bar Tio Patinhas (16) e, destacadamente, o antigo e tradicional Café Cruzeiro do Sul, citado 4 vezes com sua atual função de Dentista Popular. Os antigos cinemas, João Gomes, Presidente e Ouro Branco foram citados apenas uma vez cada, embora os edifícios tenham sido citados com seus atuais nomes e funções. A praça Monsenhor Sarrion, onde fica a Catedral, foi citada 20 vezes como praça e 4 vezes como Estacionamento, o que revela o início de um processo de perda da identidade deste espaço. As sensações atribuídas à praça são desagradáveis, com destaque para Pombos (15), Cheiro Horrível (4) e Sujeira (3).

As sensações gerais atribuídas ao centro também são, normalmente, desagradáveis. Calor (12), Grande número de pessoas (6), Movimento de trânsito (5), Movimento de pessoas (4). Liberdade foi citada apenas uma vez. 


\section{CONCLUSÃO}

A pesquisa mostra que o planejamento urbano da cidade de Presidente Prudente adote a perspectiva da imagem da cidade no direcionamento de políticas públicas. A ausência de alguns edifícios históricos importantes revela uma cidade que desconhece sua própria história e que, desta forma, desperdiça os meios de criar uma imagem forte nos parâmetros entendidos por

Kevin Lynch. Assim, o centro da cidade não é entendido em sua dimensão histórica, mas antes como um espaço popular, comercial e, ainda em algum grau, cívico. Desse modo, a possibilidade da retirada da prefeitura e câmara municipal da região em favor da criação de um novo centro cívico afastado, levantada há alguns anos pela administração municipal, não é, desta perspectiva, justificada pois contribuiria para um esvaziamento simbólico do centro da cidade.

Apesar do inegável papel afetivo e simbólico que o centro da cidade exerce sobre os prudentinos, as sensações desagradáveis a ele atribuídas sugerem o desejo de um espaço mais humano. Por um lado, atenuar o calor intenso poderia ser uma diretriz do paisagismo urbano, especialmente do calçadão. Por outro, a visão da intensa presença de carros, trânsito e estacionamentos como desagradável e perigosa dá suporte a projetos de restrição de veículos em uma área maior do que apenas o calçadão da rua Ten. Nicolau Maffei ou, pelo menos, na continuidade de políticas de priorização do pedestre que já vem sendo aplicadas como a instalação de passarelas de travessia elevadas.

Finalmente, como apontado por Borges (2016), a pesquisa revela como um grande problema a divisão causada pela linha férrea como uma cicatriz urbana no centro da cidade. A baixa qualidade de projeto e manutenção de suas travessias de pedestres, a desproporção do pontilhão utilizado para a travessia de veículos, a implantação do camelódromo que, embora já parte do imaginário bloqueia o visual entre o centro e a vila Marcondes, a topografia e as diferenças arquitetônicas e sociais entre um lado e outro reforçam esta inapropriada divisão que reclama por maiores iniciativas de integração e identificação.

\section{REFERÊNCIAS}

BORGES, Vinício. Barreiras Urbanas: Métodos de transpor. Trabalho de conclusão de curso apresentado ao curso de Arquitetura e Urbanismo da Universidade do Oeste Paulista. s/ed.: Presidente Prudente, 2016.

LYNCH, Kevin. A Imagem da Cidade. São Paulo: Martins Fonte, 2010. 2ª ed. 